UCRL- 92613

\title{
A LSI/CAMAC SYSTEM FOR HEAVY ELEMENTS RESEARCH
}

\author{
E. D. Watkins \\ R. J. Dougan \\ J. H. MeQueld
}

This peper was prepared for submittal to 4th Biennial Conference on Real-Time computer applications in nuclear and particle physics

Chicago, Tllinois
May 20-24, 1985 ,

May 2, 1985

This is a preprint of a paper intended for publication in a journal or proceedings Since changes may be made before publication, this preprint is made available with the understanding that it will not be ciled or reproduced without the permission of the author.

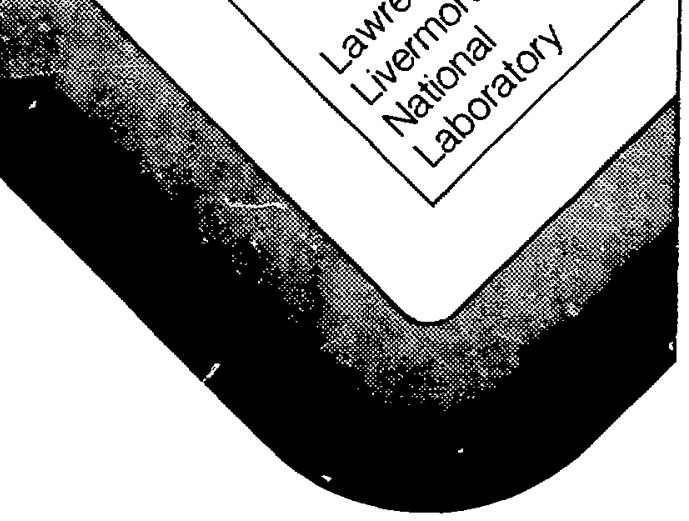




\section{Austract}

We have developed a LSI-11/23 computer-driven CAMAC data acquisition system. The 64 silicondetector system is being used to Investigate the alpha and spontaneous rission activities of short-li ved transfermium 1sotopes by the real-time monitoring of the mother-daughter alpha decay sequence. A unique modular pulse processing electronics system was deslgned to simplify set up and calibration. The computer adjusts the gain of the CAMAC shaping amplifiers enabling the calibration and alignment of all 64 of the $1 \mathrm{k}$ alpha spectra to within 0.5 channel in less than 10 minutes.

\section{Introduction}

The Nuclear Chemistry Heavy Elements group is searching for new neutron rich heavy nuclides with short half-lives that cannot be identifled by conventional techniques. The investigation of these transfermium 1 sotopes with half-lives of greater than $100 \mathrm{~ms}$ requires a unlque isotope identification method. The multiple alpha detector (MAD) system described here was developed to perform this function by the real-time monitoring of the mother-daughter alpha decay sequence, A hellum gas flow is used to transport sample materlal from a remote target chamber and deposit it on a thin plastic foll which is positioned between two annular detectors in the MAD chamber. ${ }^{1}$ Each Incoming event is inspected to see if it falls into a preset energy window. Each valid event is then time-tagged, stored, and the interval to the next related event recorded. The sample-wheel which nolds the foils is rotated by a stepping-motor to subsequent detector pairs. This complex sequence requires many counting stations. We chose 32 detector pairs initially, but the chamber design will accommodate 59 for future expansion. This paper will emphasize the unique pulse processing electronics, the need for automated set up and calibration, and the ractors which led to the choice of CAMAC design.

\section{Des1gn Considerations}

The MAD systen is located at the Lawrence Berkeley Laboratory's (LBL) 88-inch cyclotron facility, where the operating environment is relatively harsh during bombardments (e.g., radio-frequency interference, poorly controlled temperature and power distribution problems). The target chamber cave winere the sample is made gets highly radioactive during runs and is not always accessible. For these reasons, it was necessary to locate the MAD chamber and data acquisition electronics in two remote locations (FIg. 1). A separate isolated and flltered power distribution was installed for instrumentation, with a good one point grounding system. A relatively mall, well shielded, vacuum chamber was assembled to house a positlonable sample wheel and a large number of detector pairs with their associated preamplifiers. The number of counting stations requiring spectroscopy grade electronics dictated the design of a high quality, low profile plug-in preamplifier. A Camc design was chosen because of its standardized dataway comunication and the large number of comercial high

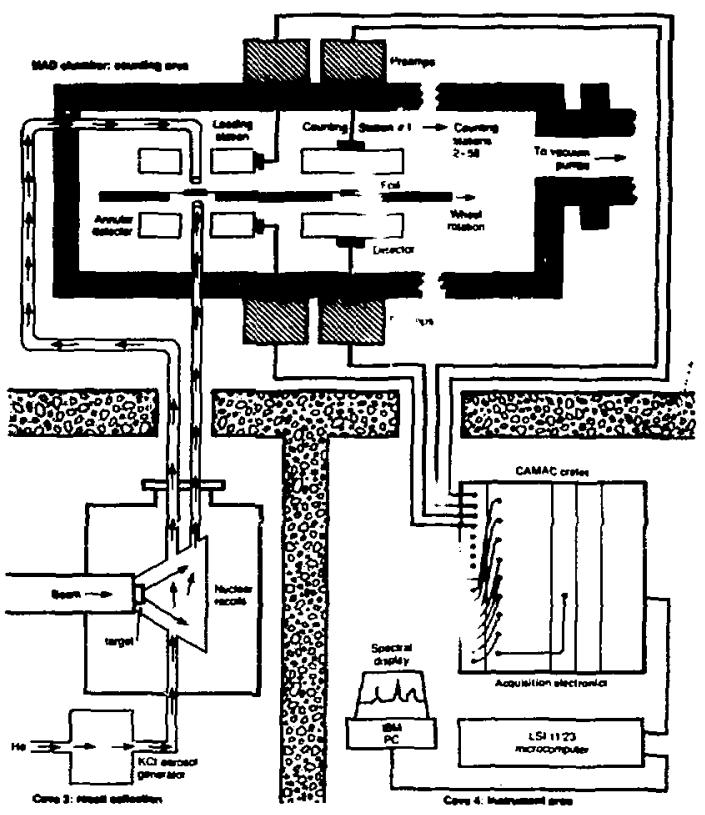

Fig. 1. MHD Sygtem Pictorial Diagram.

density data acquisition modules available. We also recognized the need for some method of autonated setup and calibration due to the difficult and time consuming job of making such a large number of manual adjustments.

\section{System Design}

The block dlagram ( $F 1 \mathrm{~g}, \vec{\varepsilon})$ shows the complete multiple detector system. The MD chamber (Fig. 3) is a stainless steel cylinder, $60 \mathrm{~cm}$ in diameter and $22 \mathrm{~cm} \mathrm{high,} \mathrm{mounted} \mathrm{on} \mathrm{a} \mathrm{metal} \mathrm{stand} \mathrm{with} \mathrm{locking}$ wheeis. The stepping-wotor sample-theel drive is mounted just below the chamber. The chamber lid has a plexiglass window to allow ylewing the detectors and sample wheel. This motor-driven lid hinges open for easy access. The Tannelec $150 \mathrm{~mm}^{2}$ slimline silicon surface barrier detectors are mounted on removable plexiglass holders in two layers. Mounted in groups of 8 , the upper 32 detectors attach to the 11d, while the opposing 32 are mounted in the botton of the chanber. These detectors are mounted on $6^{\circ}$ centers to watch the $1.5^{\circ}$ increments of the stepping motor. To minimize the number of cables and keep preamp input leads short, two large, donut shaped printed circult motherboards were designed to accept the preampliPlers. Only one calibration pulser, detector blas supply, and preanplifier power supply are used, and connect to the motherboards with a single cable. The extensive use of CAMc modules enabled us to design a relatively low cost, high quality syster having a 


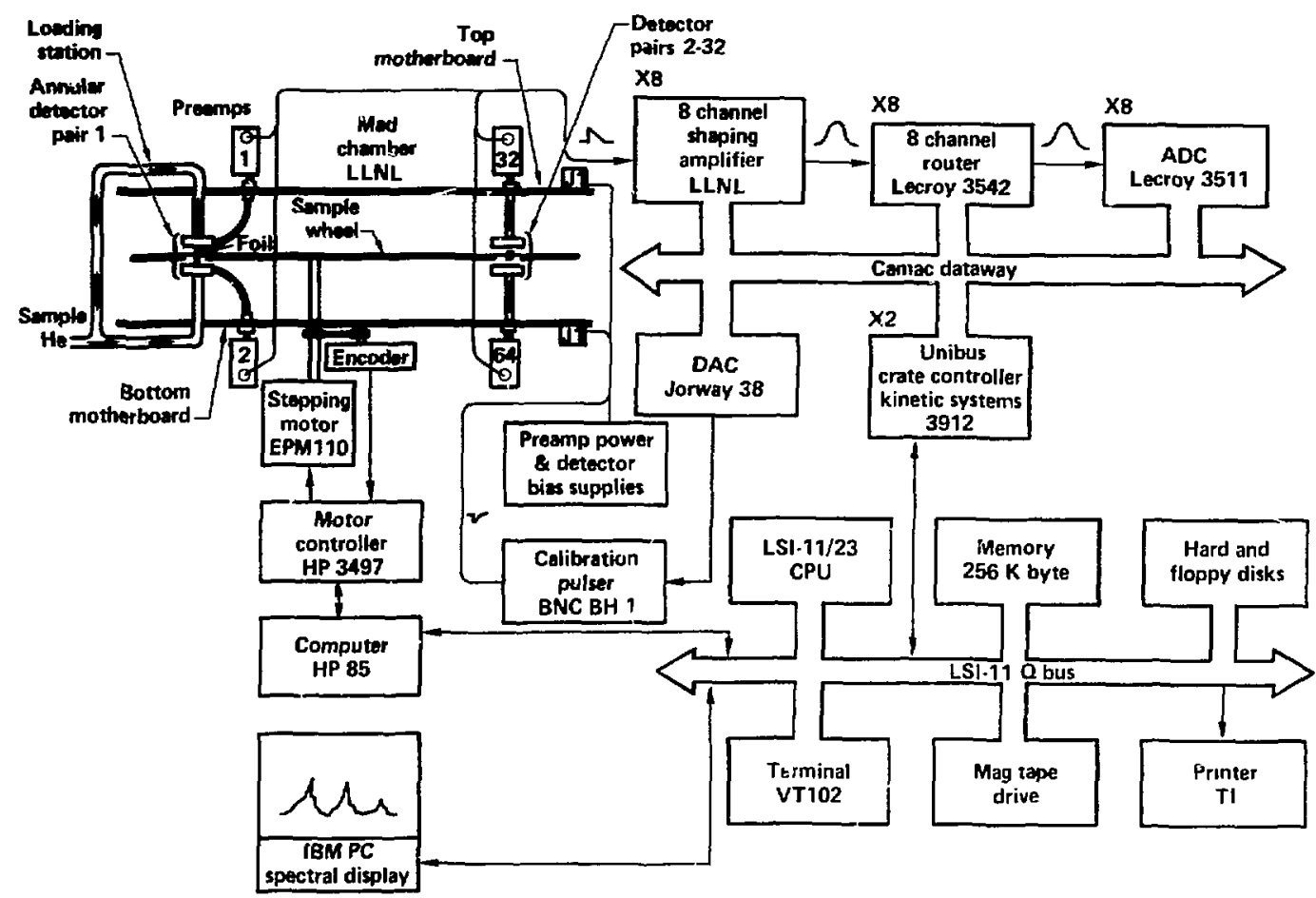

FIB. 2. Block Diagram of the MAD System.

minimum number of components. Housed in just two CAMAC crates, only two crate controllers are needed to interface the LSI-11/23 mi arocomputer to eight modular groups. Each group consists of one in-house designed 8 channel linear shaping amplifier, an 8 channel router, and one spectroscopy $A D C$.

\section{Data Acquisition}

After analog pulses from the detectors are processed and digitized by the LeCroy $A D C s$, the crate controller flags the LSI-1 $1 / 23$ computer with an interrupt request. The $[5:-11 / 23$ operates as the central processor of a computer acquisition system that.

accumulates, sorts, displays, 2 and then stores the data in a list mode fashion. A serial RS232 link establishes communication to the HPB5 computer-driven stepping-motor controller, which positions the sample wheel during acquisition. To obtain maximum data throughput, ail coding used for acquisition, inspec$t$ ion, and storage was done in machine language. Acquisition time is less than 1 ms per event.

\section{Preamplifier}

A complete clrcuit dlagram of the preamplifier is shown in Fig. 4. The small modular, plug-in preamplifier was designed for alpha spectroscopy with a linear range of $0-60 \mathrm{MeV}$, but can be easily extended to $300 \mathrm{HeV}$ for fissions. The circult is comprised of a low noise FET and a LeCroy TRA1000 monolithic amplifler conflgured as a charge loop with an output buffer to drive 50 onm coax cables. The charge loop has a gain of $0.5 \mathrm{v} / \mathrm{pC}$.

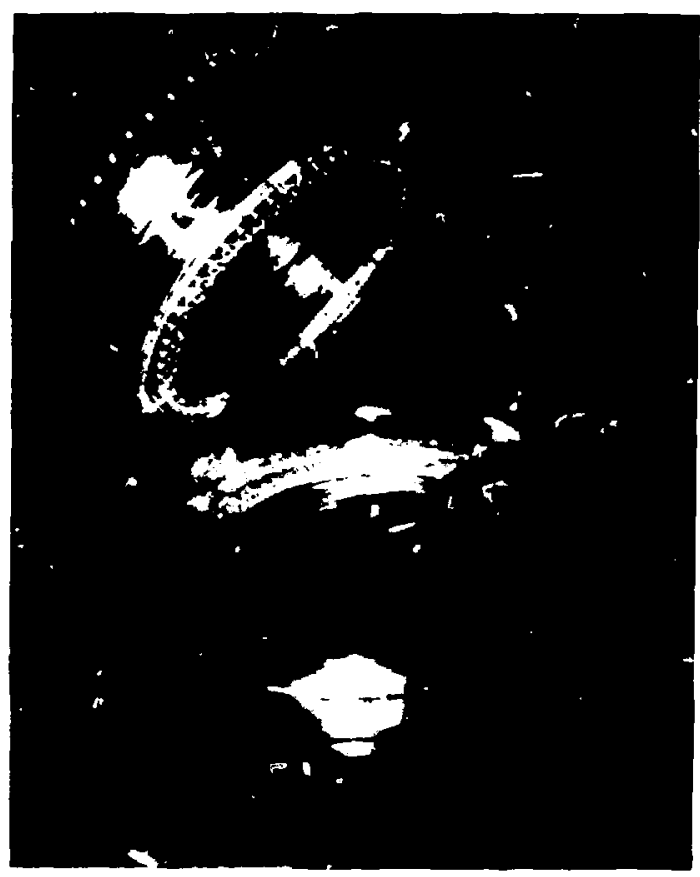

Fig. 3. The MAD Chamber. 


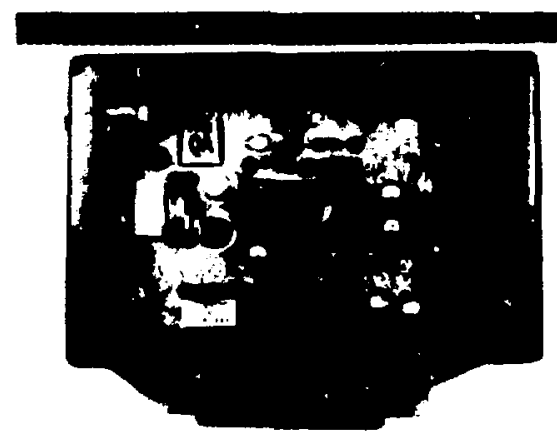

F1g. 4a. Preamplifier.

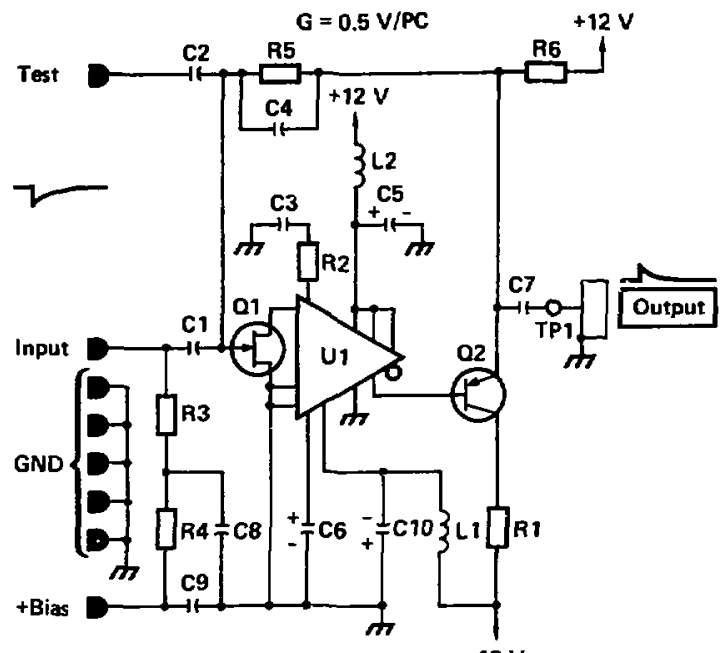

Fig. 4b. MAD Preamplifier Circuit Dlagram.

\section{Amplifler}

Since there were no commerclal camac amplifiers avallable that would meet our speciallzed require-

ments, it was decided to develop our own. ${ }^{3}$ A single width CAMAC rodule was designed having eight independent, digitally controlled shaping amplifier channels. A simplified schematic of one channel is shown in

Fig. 5. This unit was designed with pole-zero compensation, $0.5 \mathrm{~ms}$ gausslan shaping and has a digitally selectable gain of zero to sixty which ajlows for program controlled energy callaration. The gain is controlled by a 4096 attenuator which is comprised of a 12 bit multiplying digital-to-analog converter (DAC) in the reedback loop of a wideband amplifler. Although some compromises were made to get elght ampliflers in one module, the performance met all expectations.

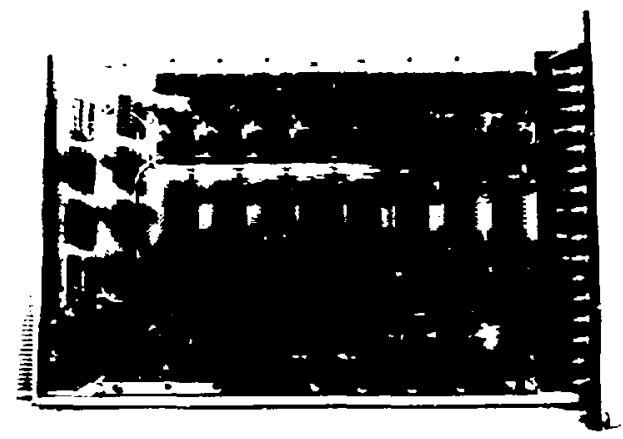

Fig. 5a. CAMAC Module.

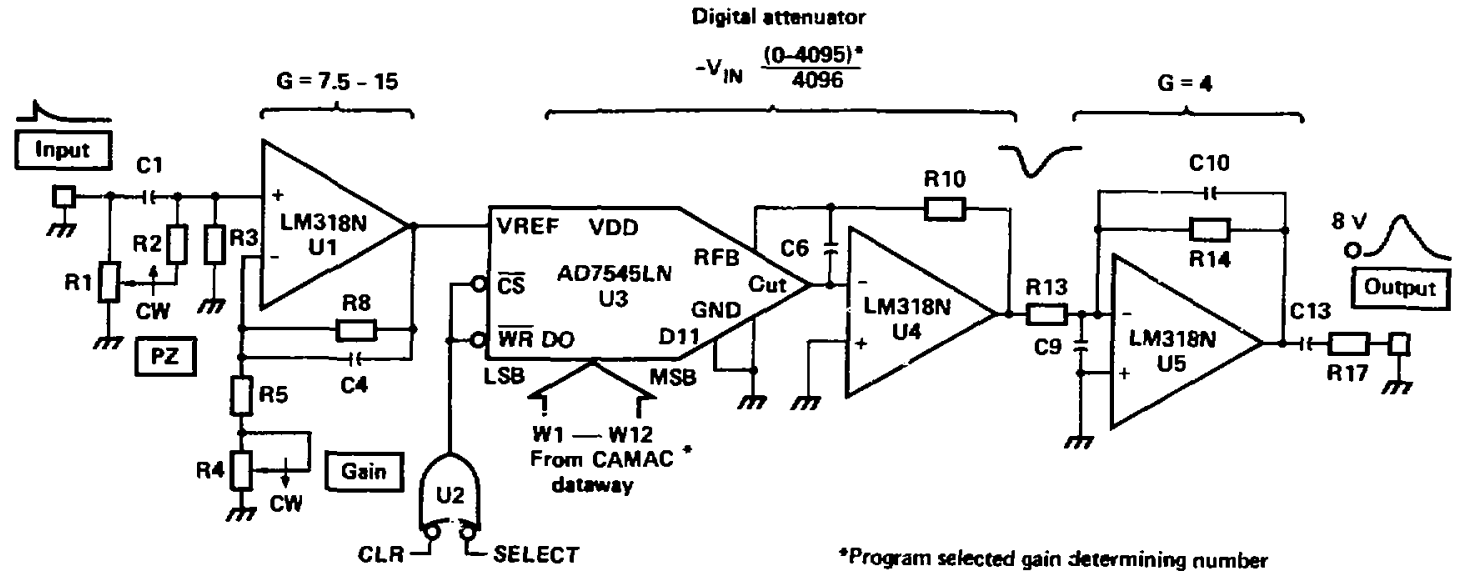

Fig. 50. Simplified CAMAC Shaping Amplifier Circult Diagram. 
The signal from a precision tall pulser is fed to the comon test input circuit of all 64 preasplifiers. A CAMAC module (Jorway DAC) provides the pulser reference voltage for energy calibration. Each automated shaping axplifier channel is then selected and gain adjusted under program control until an allgnment accuracy of 0.5 channel, In the $1 \mathrm{k}$ spectra, is achieved. Once calibrated, the inforwation is stored on disk and can be checked for stabllity during long runs. The autonatic calibration progran allows fast, accurate restoration on restart or after coiputer crashes. 11164 channels are setup in a matter of minutes vs, hours or even days, as with previous methods.

\section{Results}

The first successful experiments were done in the rall of 1984 and, over the past several months, the system has proven to be very reliable and easy to use. The resolution of the alpha peaks is limited by the close detector geometry, but less than $30 \mathrm{keV}$ FWhM resolution was attained. Because of the automated pulse processing electronics, calibration and allgnment can be done rapidly. He have developed a tocl that can be used to determine the decay properties of as yet undiscovered neutron rich lsotopes. Figure 6 shows the results of real-time sorting of motherdaughter events from the first ${ }^{263_{105}}$ search.'

\section{Acknowledgwents}

The authors wish to thank $E$. K. Hulet who initlated this development profect and provided many helpful discussions. We also thank $M$. Ochoa tho did much of the mechanical design and $D$. M. Edenburn for expediting the fabrication on a very short time scale.

Work perfomed under the ausplces of the U.S. Department of Energy by the Lawrence Livermore National Laboratory under contract number $\mathrm{H}-7405$-ENG48.

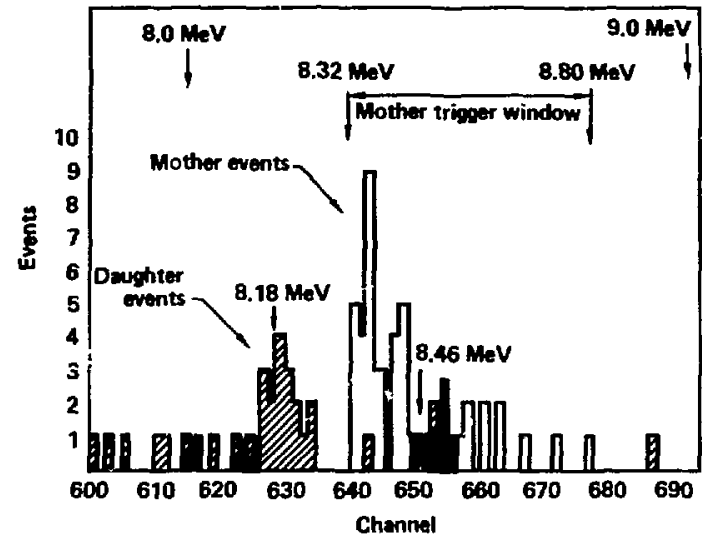

F1g. 6. Sorted Mother-Daughter Event Data.

\section{References}

1. R. J. Dougan, R. H. Lougheed, E. K. Hulet, and G. R. Bethune, HDevelopment of a Helium-Jet System for On-Line Study of Short-L 1 ved Iransf ermitm Nuclides," Nuclear Chemistry FY84 Annual Report, UCRL 10062-84/1, 2-15.

2. S. Robinson, "A Low-Cost, General Purpose Spectral Display Ifnit Using an IBM PC, "Proc, of the 6th Biennial CUBE Symposium, Los Alamos, October 10-12, 1984, LA-10240-C, P. 66.

3. E. Hatkins, "CAMC Dctal Shaping Amplifier," LLNL D\&I, LEAB4-1410-02-D, October, 1984.

\section{DISCLAIMER}

This report was prepared as an account of work sponscred by an agency of the United States Government. Neither the United States Government nor any agency thereof, nor any of their employees, makes any warranty, express or implied, or assumes any lagal liability or responsibility for the accuracy, completeness, or usefulness of any information, apparatus, product, or process disclosed, or represents that its use would not infringe privately owned rights. Reference herein to any specific commercial product, process, or service by trade name, trademark, manufacturer, or aberwise does pol necessarily constitute or imply its endorsement, recommendation, or favoring by the United States Government or eny egency thereof. The views and opinions of authors expressed herein do not necessarily state or reflect thoue of the United States Government or any agency thereor. 